\title{
Effectiveness of Planned Teaching Program on Knowledge of Primigravidae regarding Selected Aspects of Safe Motherhood
}

\author{
Anupama Tamrakar ${ }^{1}$, S. Nagaseshamma ${ }^{2}$ \\ ${ }^{1}$ Lecturer, Dept of OBG Nursing, Yenepoya Nursing College, Mangalore, Karnataka, India) \\ ${ }^{2}$ Professor, HOD, Dept of OBG Nursing, AECS Pavan College of Nursing, Kolar, Karnataka, India)
}

\section{Introduction}

Every woman during her life span aspires to be a mother but the child birth process is not free of complication. Several complications may arise in different stages of her motherhood i.e., in pregnancy, intranatal and postnatal period. These complications increase the risk of maternal mortality and morbidity. Mothers play vital role in the family. Maternal deaths have negative effects to their family and increase the risk to the survival of their children too. Hence importance of good health and education to a mother's well-being and that of her family and society cannot be overstated. Addressing maternal health means ensuring that all women receive the care they need to be safe and healthy throughout pregnancy and childbirth. Safe motherhood encompasses social and cultural factors, as well as addresses health systems and health policy. Improving maternal health is one of the eight Millennium Development Goals, and great efforts have been put forth to achieve that goall. Safe motherhood comprise care of mothers in antenatal, intranatal and postnatal period. The ultimate goal of Safe motherhood program in India is to bring down the maternal mortality rate ${ }^{1}$.

Every day, approximately 800 women die from preventable causes related to pregnancy and childbirth around the world. Among those deaths, ninety nine percentages of all maternal deaths occur in developing countries. Maternal mortality is higher in women living in rural areas and among poorer communities ${ }^{2}$. India has high maternal mortality rate. The trend report shows that from 1990 to 2010, the annual number of maternal deaths dropped from more than 543,000 to 287,000 - a decline of 47 percent. But still the maternal mortality remains high. The current Maternal Mortality Rate (MMR) of India is 212 per one lakh live births. This data shows that there is reduction in the MMR in the year of 2010 which recorded 150 women dying per day and 10 women in every minute ${ }^{3}$.

Every pregnancy is at risk and may give rise to complications at any time which may further develop life threatening complications if not managed properly and timely. The data reveals high death in pregnancy. Every two minutes, a woman dies of pregnancy-related complications, the four most common causes being: severe bleeding after childbirth, infections, high blood pressure during pregnancy, and unsafe abortion. Ninety-nine percent of maternal deaths occur in developing countries; most could have been prevented with proven interventions ${ }^{4}$.

Preventing maternal death and illness is a social justice. Making motherhood safer is essential to reduce the maternal mortality and morbidity. This can be done by various activities like providing quality care to the mothers during antenatal, intranatal and postnatal period, creating the awareness regarding care during these natal periods and building the capacity of health workers through trainings and workshops. One of the crucial factors in high maternal mortality and morbidity is the lack of awareness about the antenatal care. Thus providing the information regarding the antenatal care is important among the antenatal mothers. Hence, in this study, researcher tried to evaluate the effectiveness of planned teaching program regarding antenatal care, a selected aspect of safe motherhood.

\subsection{Methods}

\section{Methods and Materials}

A true experimental, control group pre-test post-test design was performed among randomly selected 100 primigravidae in second trimester (50 in control group and 50 in experimental group). The study was conducted in Hope Health Care Hospital and Suguna Hospital of Kolar district in Karnataka.

\subsection{Materials}

A structured interview schedule was developed to assess the effectiveness of planned teaching program on knowledge regarding antenatal care among primigravidae. The tool consisted of Section-A and Section-B. Section-A consisted the demographic variables. Section-B included the knowledge regarding antenatal care, divided in different groups as general questions, diet during pregnancy, personal hygiene, antenatal check-up, immunization in pregnancy and other care during antenatal period. 


\subsection{Validity, Reliability of Tool and Pilot study}

The developed tool was given for validity for ten experts. Suggestions given by experts were subsequently incorporated into the tool. In order to establish the reliability, the tool was administered among 20 primigravidae. Split half method was applied and reliability co-efficient was calculated by using Spearman Brown's formula. The tool was found to be highly reliable as the calculated reliability was 0.98 . Pilot study was conducted from 1st to 9th Feb 2007 among 10 primigravidae attending antenatal clinics of Suguna hospital, Kolar. The result of the pilot showed that the tool and methodology of the study was feasible, practicable and acceptable.

\subsection{Data Collection}

Prior to the data collection, permission was obtained from the concerned authority of the selected hospitals and informed consent from the participants. They were also assured for the confidentiality of the information. Primigravidae attending antenatal clinic of Suguna hospital were taken in experimental group and those attending antenatal clinic of Hope health care were taken as control group. Data was collected from $12^{\text {th }}$ February to $11^{\text {th }}$ March 2007. Pre-test of knowledge regarding antenatal care was conducted in both control and experimental groups. Planned teaching program was implemented in participants of experimental group only on the same day of the pre-test. Post-test was conducted after 7 days of the pre-test in both groups.

Data was analyzed using descriptive and inferential statistics. Frequency and percentage were calculated for the demographic characteristics of postnatal mothers and percentage, mean, standard deviation, mean percentage were calculated for knowledge level. To see the effectiveness of planned health education, " $\mathrm{t}$ " test was calculated and chi-square test was calculated to see the association between the selected demographic variables and knowledge scores.

\subsection{Demographic Characteristics of the Primigravidae}

\section{Results}

The study sample consisted of primigravidae between the age group of $20-40$ years who are in second trimester. Majority of the primigravidae, $74 \%$ in the experimental group and $86 \%$ in control group were in the age group of 20-24 years and 98\% of both groups were Hindu. Maximum participants had attended primary level of education (78\% in experimental group and 58\% in control group) and more than half of them were housewives (68\% in experimental group and $64 \%$ in control group). More than fifty percentages of both groups were from joint family and most of them were having monthly income of Rs. 1,001- Rs. 5,000. Half of the participants married at the age of less than 20 years and majority of them (74\%) in experimental group had heard about antenatal care whereas, only $44 \%$ of control group had heard about it. The major source of information was elders and relatives. The information is depicted in details in Table 1.

\subsection{Findings Related to Knowledge and Effectiveness of Planned Teaching Program}

The pre-test knowledge score depicted that more than two third of the participants (88\% in the experimental group and $78 \%$ in the control group) had moderately adequate knowledge regarding antenatal care. The post test score demonstrated there was increment in the knowledge of the participants in experimental group as more than half of the participants in the experimental group (58\%) had adequate knowledge which may be due to the implementation of planned teaching program. Maximum of the participants in the control group $(84 \%)$ had moderately adequate knowledge in the post test. Analysis within the groups showed that in the experimental group, the mean pre-test knowledge score was $22.9 \pm 3.2$ whereas post test score mean was 30.26 \pm 2.6 . Similarly, in the control group, the mean pre-test knowledge score was $23.06 \pm 3.6$ whereas post test score mean was $24.01 \pm 3.3$.

The calculated " $\mathrm{t}$ " value was 20.07 which showed $\mathrm{p}<0.000$ level of significant which indicated the significant difference in the level of knowledge before and after the implementation of planned teaching program. The " $\mathrm{t}$ " value calculated in control group also divulged that there is the significant difference in pretest and post test knowledge level as $\mathrm{p}$ value was less than 0.05 level. The student " $\mathrm{t}$ " value calculated between the pre-test of experimental and control groups was found to be 0.115 ( $\mathrm{P}>0.05)$. This indicated that there was no significant difference in the level of pre-test knowledge among primigravidae of both groups. The calculated student " $t$ " value between the post-test of both groups was found to be $3.36(\mathrm{P}<0.05)$. 
Hence, it was found that there is significant difference between the post-test knowledge among primigravidae of both groups. This revealed that planned teaching knowledge was effective. The details of the findings are summarized in figure 1 , table 2,3 and 4.

\subsection{Findings Related with Factors Associated with Knowledge Regarding Antenatal Care}

The findings of the study also illustrated that there was the significant relationship between the pre-test knowledge scores and age $(\mathrm{P}<0.000)$, occupation $(\mathrm{P}<0.05)$ and family income $(\mathrm{P}<0.000)$ in the experimental group. Similarly in the control group, there was significant relationship between the knowledge scores and age and family income of the respondents $(\mathrm{P}<0.05)$. The details are recapitulated in Table 5.

Table 1. Frequency and Percentage Distribution of Sample Characteristics

\begin{tabular}{|c|c|c|c|c|c|}
\hline \multirow{2}{*}{$\begin{array}{l}\text { Sl. } \\
\text { No. }\end{array}$} & \multirow[t]{2}{*}{ Demographic variables } & \multicolumn{2}{|c|}{ Experimenal Group } & \multicolumn{2}{|c|}{ Control Group } \\
\hline & & Frequency & Percentage & Frequency & Percentage \\
\hline \multirow[t]{5}{*}{1.} & Age in Years & & & & \\
\hline & $20-24$ & 37 & 74 & 43 & 86 \\
\hline & $25-29$ & 12 & 24 & 6 & 12 \\
\hline & $30-34$ & 1 & 2 & 1 & 2 \\
\hline & $35-40$ & 0 & 0 & 0 & 0 \\
\hline \multirow[t]{4}{*}{2.} & Religion & & & & \\
\hline & Hindu & 49 & 98 & 49 & 98 \\
\hline & Christian & 0 & 0 & 0 & 0 \\
\hline & Muslim & 1 & 2 & 1 & 2 \\
\hline \multirow[t]{5}{*}{3.} & Educational Status & & & & \\
\hline & Illiterate & 4 & 8 & 7 & 14 \\
\hline & Primary & 37 & 74 & 29 & 58 \\
\hline & Higher secondary & 7 & 14 & 6 & 12 \\
\hline & Graduation \& post-graduation & 2 & 4 & 8 & 16 \\
\hline \multirow[t]{5}{*}{4.} & Occupational Status & & & & \\
\hline & House wife & 34 & 68 & 32 & 64 \\
\hline & Agriculture & 14 & 28 & 14 & 28 \\
\hline & Government employee & 1 & 2 & 1 & 2 \\
\hline & Private employee & 1 & 2 & 2 & 4 \\
\hline \multirow[t]{4}{*}{5.} & Type of Family & & & & \\
\hline & Nuclear & 22 & 44 & 22 & 44 \\
\hline & Joint & 27 & 54 & 28 & 56 \\
\hline & Extended & 1 & 2 & 0 & 0 \\
\hline \multirow[t]{5}{*}{6.} & Family Income/Month & & & & \\
\hline & $<$ Rs. 1,000 & 3 & 6 & 4 & 8 \\
\hline & $1,001-5,000$ & 40 & 80 & 30 & 60 \\
\hline & Rs.5,001-10,000 & 6 & 12 & 10 & 20 \\
\hline & $>$ Rs. 10,000 & 1 & 2 & 6 & 12 \\
\hline \multirow[t]{4}{*}{7.} & Age at Marriage & & & & \\
\hline & $<20$ years & 25 & 50 & 25 & 50 \\
\hline & $20-24$ years & 23 & 46 & 23 & 46 \\
\hline & $25-29$ years & 2 & 4 & 2 & 4 \\
\hline \multirow[t]{4}{*}{8.} & Pre-existing Information on Antenatal & & & & \\
\hline & Care & 37 & 74 & 22 & 44 \\
\hline & Yes & 13 & 26 & 28 & 56 \\
\hline & No & & & & \\
\hline \multirow[t]{5}{*}{9.} & Source of Information & & & & $\mathbf{n}=\mathbf{3 7}$ \\
\hline & Mass media & 0 & 0 & 7 & 18.9 \\
\hline & Health personnel & 12 & 32.4 & 3 & 8.1 \\
\hline & Elders and relatives & 25 & 67.6 & 11 & 29.7 \\
\hline & Others & 0 & 0 & 1 & 2.7 \\
\hline
\end{tabular}


Figure 1. Description of the Pre-test and Post-test Knowledge Scores of Primigravidae of Experimental and Control Groups regarding Antenatal Care.

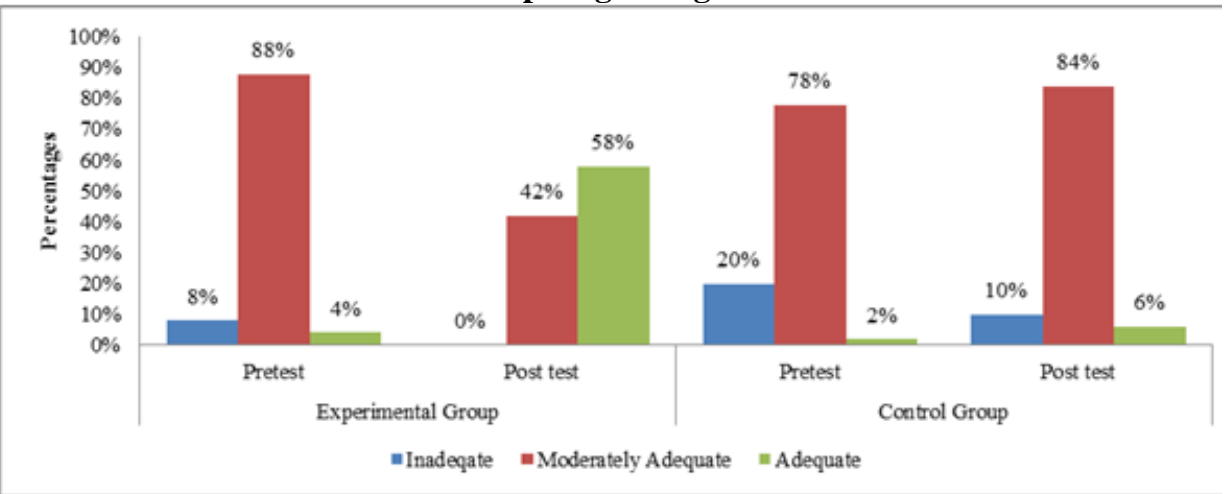

Table 2. Description of Knowledge Scores of Both Groups according to Areawise Questions

\begin{tabular}{|c|c|c|c|c|c|c|c|c|c|}
\hline \multirow[t]{3}{*}{ Areas } & \multirow[t]{3}{*}{ Scores } & \multicolumn{4}{|c|}{ Experimental Group } & \multicolumn{4}{|c|}{ Control Group } \\
\hline & & \multicolumn{2}{|c|}{ Pre-test } & \multicolumn{2}{|c|}{ Post test } & \multicolumn{2}{|c|}{ Pre- test } & \multicolumn{2}{|c|}{ Post test } \\
\hline & & $\mathbf{M}$ & SD & $\mathbf{M}$ & SD & $\mathbf{M}$ & SD & $\mathbf{M}$ & SD \\
\hline General Questions & 5 & 3.5 & 1.01 & 4.3 & 0.5 & 3 & 1.2 & 3.6 & 1.03 \\
\hline Antenatal Diet & 12 & 6.5 & 1.5 & 8.8 & 1.5 & 6.6 & 1.9 & 6.6 & 1.5 \\
\hline Personal Hygiene & 3 & 2.1 & 0.7 & 2.5 & 0.8 & 1.4 & 0.8 & 1.8 & 0.8 \\
\hline Antenatal & 5 & 3.1 & 0.8 & 3.7 & 0.7 & 3.1 & 1.05 & 3.2 & 0.8 \\
\hline Immunization & 6 & 3.2 & 1.1 & 4.4 & 0.9 & 3.7 & 1.08 & 3.6 & 0.9 \\
\hline Other Questions & 8 & 4.4 & 1.2 & 6.3 & 1.2 & 5.1 & 1.3 & 5.1 & 1.4 \\
\hline
\end{tabular}

Table 3. Effectiveness of Planned Teaching Program within the Experimental and Control Groups

\begin{tabular}{|c|c|c|c|c|c|c|c|c|c|c|}
\multicolumn{10}{c|}{$\mathrm{n}=50$} \\
\hline
\end{tabular}

Table 4. Description of Unpaired " $t$ " test between the Pre-tests and Post-tests of Both groups

\begin{tabular}{|c|c|c|c|}
\multicolumn{2}{|c}{$\mathrm{n}=50$} \\
\hline Pre-test & Calculated “t” value & Table "t" value & Significance \\
\hline Post-test & 0.115 & 1.96 & $\mathrm{P}>0.05(\mathrm{NS})$ \\
\hline
\end{tabular}

Key: NS indicates not significant and S indicates significant.

Table 5. Association between the Knowledge Scores and Selected Demographic Variables

\begin{tabular}{|c|c|c|}
\hline \multirow{2}{*}{ Demographic Variables } & Experimental Group & Control Group \\
\cline { 2 - 3 } & $\chi^{2}$ Value & $\chi^{2}$ Value \\
\hline Age & $34.0^{*}$ & $34.4^{*}$ \\
\hline Religion & 6.2 & 9.1 \\
\hline Education & 24.2 & 23.7 \\
\hline Occupation & $60.2^{*}$ & 24.6 \\
\hline Family Income & $43.7^{*}$ & $49.9^{*}$ \\
\hline
\end{tabular}

Key: * indicates significant. 


\section{Discussion}

Findings revealed that more than two third of the participants had moderately adequate knowledge regarding antenatal care according to pre-test score. The post test score demonstrated the increment in the knowledge of the participants in experimental group as more than half of the participants in the experimental group $(58 \%)$ had adequate knowledge which may be due to the implementation of planned teaching program. Maximum of the participants in the control group (84\%) had moderately adequate knowledge in the post test. This finding is supported by a study conducted in Pakistan which revealed that there is a lack of information of antenatal services.

In the experimental group, the mean pre-test knowledge score was $22.9 \pm 3.2$ and standard error of whereas post test score mean was $30.26 \pm 2.6$. Similarly, in the control group, the mean pre-test knowledge score was $23.06 \pm 3.6$ whereas post test score mean was $24.01 \pm 3$.3. There was the significant difference in the level of knowledge before and after the implementation of planned teaching program $(p<0.000)$. Findings also revealed that there was significant difference in the level of post-test knowledge among primigravidae of both groups. This revealed that planned teaching knowledge was effective. Correspondingly, findings of a study conducted by Nuraini E and Parker E which also demonstrated that the improvement of knowledge after the teaching program in the intervention group is significant particularly in the knowledge about healthy pregnancy $(\mathrm{p}=0.012)$, pregnancy complications $(\mathrm{p}=0.01)^{6}$.

The findings of the study also illustrated that there was the significant relationship between the pre-test knowledge scores and age, occupation and family income in the experimental group. This finding was supported by the study conducted by Nuraini E and Parker E which also indicated improvement of knowledge was significantly influenced by the respondents' educational back ground $(\mathrm{p}=0.002)$ and socio-economic status $(\mathrm{p}=0.027)^{6}$. In the control group, there was no significant relationship between the knowledge scores and any of the demographic variables.

\section{Conclusion}

The study disclosed that more than two third of the participants had moderately adequate knowledge regarding antenatal care before the teaching program. The post test score demonstrated the vast increment in the knowledge of the participants in the experimental group whereas; in the control group also there was a slight increment of knowledge in post-test. The findings of the study also illustrated that there was significant relationship between the pre-test knowledge scores and age, occupation and family income in the experimental group.

Hence, it is concluded that the planned teaching program was effective to increase the knowledge regarding the antenatal care, one of the important aspect of safe motherhood. Education regarding antenatal care should be given to all pregnant mothers to make their motherhood period healthy and safe and to bring good pregnancy outcome which may aid in reducing maternal morbidity and mortality rates which further can help to achieve millennium development goal 4,5 and 3. Nursing students, peer groups can be mobilized to conduct these educational programs. All women and their husbands should be educated on antenatal care and motivated to adopt it. In addition to this, further researches should be conducted to cover other areas and different part of the country in terms of knowledge, attitudes and practice on antenatal care.

\section{Acknowledgement}

My special thanks go to the management of hospitals for permitting me to conduct this study. I am thankful to all the participants of my study. My sincere gratitude to Prof. Shanta Kumari, Yenepoya Nursing College for her support and motivation for the publication.

\section{References}

[1]. The World Bank: Population and Reproductive Health. Safe Motherhood and Maternal Health. 2013. Available from: URL: http://go.worldbank.org/V5EPGZUL40

[2]. WHO. Maternal Mortality. Fact sheet No. 348. May 2012. Available from: WHO media centre. mediainquiries@who.int.

[3]. UN. A maternal death every 10 minutes in India. Last Updated: Tuesday, July 03, 2012, 08:55. Available from: zeenews.india.com/exclusive/a-maternal-death-every-10...

[4]. UNFPA - Maternal Deaths Halved in 20 Years, but Faster Progress. The report "Trends in maternal mortality: 1990 to 2010". 16 May 2012. Available from: http://www.unfpa.org/public/home/news/pid/10730.

[5]. Ghaffar A, Pongpanich S, Robert S. Chapman, AP, Mureed S, Ghaffar. Provision and utilization of routine antenatal care in rural Balochistan Province, Pakistan: A survey of knowledge, attitudes, and practices of pregnant women. Journal of Applied Medical Sciences, 2012; 1(1), 93-116. ISSN: 2241-2328 (print version), 2241-2336 (online) Scienpress Ltd, 2012.

[6]. Nuraini E, Parker E. Improving knowledge of antenatal care among pregnant women: a field trial in central Java, Indonesia. Asia Pac J Public Health. 2005;17(1):3-8. 